\title{
LA PREVALENCIA COMO PRECURSOR ÉTICO PRIMORDIAL. (DE SPINOZA A DAMASIO)
}

\author{
Juan Bosco González \\ juanbosco.gd@gmail.com
}

\section{Resumen}

El presente artículo pretende esclarecer hechos y aportar motivos que pudieran dar lugar a considerar la posibilidad de la existencia de disposiciones naturales que, en ese caso, debieran ser consideradas como precursores éticos. Dado que la propuesta neuroética centra la atención y el estudio en el cerebro humano para llevar a cabo la búsqueda de tales disposiciones naturales, se plantea en este texto una cuestión de partida: ¿es posible ir más allá del cerebro en esa búsqueda? O mejor, ‘antes? A este respecto, Baruch Spinoza traza en su Ética líneas de reflexión que se antojan susceptibles de ser tenidas en cuenta y que conectan de una interesante manera con los recientes trabajos del neurocientífico Antonio Damasio.

PALABRAS ClaVe: evolución, ética, homeostasis, supervivencia, prevalencia, vida.

\section{PREVALENCE AS A PRIMARY ETHICAL PRECURSOR. \\ (FROM SPINOZA TO DAMASIO)}

\section{Abstract}

This article aims to clarify facts and contribute reasons that could lead one to consider the possibility of the existence of natural dispositions which, in that case, should be considered as ethical precursors. Given that the neuroethics proposal focuses attention and studies on the human brain in order to carry out the search of those natural dispositions, this text suggest an initial question: is it possible to go beyond the brain in that search? Or even better, before it? In this regard, Baruch Spinoza proposes lines of reflection in his Ethics which appear susceptible to be taken into account and that, interestingly, connect with the recent works of the neuroscientist Antonio Damasio.

KEYwORDs: evolution, ethics, homeostasis, survival, prevalence, life. 


\section{UN MÉTODO ANTE TRES SESGOS}

La cuestión sobre el origen de la dimensión ética del ser humano es un debate abierto en el que confluyen, o debieran confluir, numerosas disciplinas, pero esa apertura no es, a mi juicio, tanto un ejercicio activo de análisis compartido y objetivo como, más bien, al menos de momento, una suerte de punto de fuga urgente observado desde el acotamiento teórico y conceptual de dichas disciplinas, en el fondo convergentes. Expresándolo de otra manera, parece haber ciertos sesgos que dificultan la confluencia a pesar de la convergencia. Quizás es necesario olvidar el punto de fuga y desarrollar una estrategia diferente que podría considerar como elemento de partida una premisa sencilla usando como soporte a Spinoza y la afirmación que en el Escolio de la Proposición xxix de la Parte Primera de su Ética realiza respecto de la naturaleza: cuanto es en sí y por sí ha de considerarse Naturaleza Naturante, y los modos en que se expresa cuanto es en sí y por sí han de considerarse Naturaleza Naturada ${ }^{1}$. La premisa sería esta: todo es naturaleza; por tanto, todo es natural. A riesgo de parecer próximo a las tesis de Julian Huxley o incluso del mismísimo Teilhard de Chardin ${ }^{2}$, con la búsqueda, en ambos casos, de una visión integradora de la realidad desde la perspectiva progresionista ${ }^{3}$ de la evolución -con la salvedad del objetivo, preexistente en el caso de Teilhard y ausente en el caso de Huxley-, ¿por qué no superar la disgregación teórica? Dicho de otro modo, ¿por qué tener por naturales unas cosas y otras no, aun teniendo lugar todas en la naturaleza y por

${ }^{1}$ La naturaleza naturante como causa libre, que nombra Spinoza como substancia o Dios, no difiere en absoluto de la idea de naturaleza como realidad todoabarcante, si se me permite el palabro, a la que se acercan las disciplinas científicas desde sus respectivas parcelas de saber en la actualidad. Cf. Spinoza, Ética, I, 29, Escolio (Spinoza, Ética, Ed. Alianza, Madrid, 2018).

${ }_{2}^{2}$ En el epílogo del extraordinario texto de Juan Luis Arsuaga, Vida, la Gran Historia, el paleontólogo realiza una comparativa de las diferentes perspectivas científicas desarrolladas sobre la evolución, evidentemente desde Darwin, quien la formulara como teoría con su El Origen de las Especies. Como en todos los campos de estudio científico, la historia de la ciencia está repleta de personajes ilustres que, sencillamente, quedaron en el camino, bien porque sus posiciones han resultado insostenibles a la luz de los hallazgos, o bien, como en el caso de Huxley y Chardin, porque, como indica Arsuaga, dieron un paso más allá de la ciencia y formularon hipótesis tan alejadas del paradigma y tan difíciles de encajar epistemológicamente que terminaron siendo calificados, si no señalados peyorativamente, como visionarios. En ese sentido, sostiene Arsuaga que, aunque transitando caminos intelectuales distintos, ambos pensadores compartían objetivo: borrar los límites entre lo natural y lo sobrenatural, que no es muy distinto de borrar los límites entre lo objetivo y lo subjetivo, cf. Vida, la Gran Historia, Destino, Barcelona, 2019.

3 Utilizo como texto de referencia para abordar la evolución esta obra de Juan Luis Arsuaga antes referenciada por tratarse de un amplio estudio sobre la historia evolutiva y de las teorías derivadas de las diferentes posturas adoptadas por la comunidad científica ante el darwinismo. En el epílogo, respecto de la polémica idea de progreso en la evolución, Arsuaga contrasta la visión progresionista con la evolucionista, conteniendo la primera la afirmación de una tendencia de progreso global de la evolución hacia una mayor adaptabilidad, que culminaría, además, en la evolución humana como vanguardia evolutiva, y la segunda la afirmación de que ese progreso es un efecto colateral de la adaptabilidad y, en cualquier caso, local, puesto que la evolución es ciega y no favorece a ninguna especie en concreto. 
causa de esta? ¿O solo es natural aquello que es susceptible de ser observado, medido y reducido a fórmula matemática? ¿Cómo cuantificar una emoción, un sentimiento, una ensońación, una idea? La neurociencia se abre paso en este dilema mediante el análisis de las funciones y estructuras cerebrales, así como de los múltiples procesos neurológicos que acontecen en el órgano rector de la conducta y el organismo humanos, pero la experiencia subjetiva no es abordable salvo en términos interpretativos sin embargo, es real y natural, porque sucede en la inmensa trama neuronal, luego todo fenómeno mental, toda percepción, emoción, sensación, sentimiento y pensamiento, también, porque tienen lugar en y por causa de la naturaleza. ¿Cómo no considerar, entonces, natural toda experiencia humana? ¿Cómo no considerar natural la singularidad de la humanidad, tomando esta como cualidad? ¿Cómo no considerar natural la expresión de esa singularidad en lo que hemos convenido en llamar valores? ¿Cómo no considerar natural, pues, la ética en la medida en que habría de contemplarse como un fenómeno experiencial emergente de la singularidad humana, aun planteándose, incluso, como producto cultural? No hacerlo vendría a resultar dar valor a la causa en detrimento de su efecto, cuando causa y efecto son un binomio indisoluble, o peor aún, en el caso de la ética, sería desligarla de la naturaleza por no ser abordable desde parámetros propiamente científicos, produciéndose, entonces, una clara contradicción: si no es observable ni cuantificable no cuenta como objeto científico, que en ciencia viene a ser casi como si no existiera, quedando relegada, por su subjetividad, al ámbito de lo meramente cultural, pero ¿no hablamos ya de cultura en términos evolutivos? ¿No es la cultura un proceso derivado de la evolución, condicionado, además, como veremos, por los mecanismos básicos de la vida? ${ }^{24}$ Reduciéndolo a la máxima simplicidad: no puede haber en la naturaleza algo que no sea natural -la rotundidad argumentativa de Spinoza es clarificadora en este sentido-, así que la ética es, necesariamente, natural, y hay

${ }^{4}$ El físico Jorge Wagensberg, en su libro Teoría de la Creatividad (Tusquets. Barcelona, 2017), define la cultura como un logro de la selección natural basado en la utilidad cuyo proceso se activa en el instante en que el cerebro adquiere nuevas cualidades en el Homo habilis a partir de ver libres sus manos. Se trata de un punto de inflexión que desata lo que Yuval Harari considera una revolución, en este caso cognitiva, a partir de la cual la relación entre la historia y la biología es indisociable si lo que se pretende es ahondar en la comprensión de lo humano. Lo resume Harari de esta manera: «Toda la historia tiene lugar dentro de los límites de esa liza biológica. Sin embargo, esta liza es extraordinariamente grande, lo que permite que los sapiens jueguen a una asombrosa variedad de juegos [...] cada vez más complejos, que cada generación desarrolla y complica todavía más. En consecuencia, para poder comprender de qué manera se comportan los sapiens, hemos de describir la evolución histórica de sus acciones», cf. Harari, Y.N., Sapiens. De animales a dioses. Debate, Barcelona, 2015, p. 53. Indudablemente, esa revolución cognitiva representa un salto de cualidad por la eclosión del lenguaje y, con este, la construcción progresiva de un mundo simbólico y abstracto no solo expresado en palabras, sino en frases elaboradas con palabras, es decir, ideas verbalizadas que requieren sintaxis y, además, representaciones que, en un nivel básico, son comunes en la especie humana. El paleontólogo Juan Luis Arsuaga recurre al fenómeno de los emoticonos de nuestros dispositivos móviles: tienen un sentido y significado universales más allá del componente idiomático, lo cual basta, a su juicio, para ver «cómo la biología y la cultura conviven y se complementan en los seres humanos", $c f$. Arsuaga, op. cit. 
en su manifestación como experiencia humana un evidente sustrato evolutivo y, en consecuencia, biológico que no solo requiere atención, sino que supone una oportunidad científica extraordinaria de investigación integrada, como promueve, por ejemplo, el materialismo ilustrado ${ }^{5}$ desde el que, por ejemplo, Kathinka Evers desarrolla su propuesta neuroética. Por otro lado, no deja de percibirse otro sesgo más, aunque sutil, de índole mecanicista que se me ocurre definir de este modo: la atención a lo particular impide, e incluso altera, la percepción de lo general. Me explico. Incluso en el materialismo ilustrado, aunque de modo tenue, el efecto vuelve a estar subordinado a la causa, puesto que la búsqueda de esta corre peligro de convertirse en una suerte de reduccionismo que pretende dar, en este caso, con la estructura orgánica concreta que hace posible todo el proceso de la conciencia y, por extensión, «sostiene» los valores, cuando la realidad objeto de análisis ha de ser el proceso en sí, que incluye aquello en lo que este deviene como fenómeno emergente. Cabe recurrir a la analogía de la liquidez del agua de John Searle $:$ «La conducta de las moléculas de $\mathrm{H}_{2} \mathrm{O}$ explica la liquidez, pero las moléculas individuales no son líquidas» ${ }^{7}$; dicho de otra manera: el agua está compuesta por dos átomos de hidrógeno y uno de oxígeno $\left(\mathrm{H}_{2} \mathrm{O}\right)$, pero el hidrógeno no es agua y el oxígeno tampoco. $\mathrm{Si}$ ubico mi atención en las partes, hidrógeno y oxígeno, pierdo de vista el agua y sus propias cualidades como realidad emergente específica. Sobra a estas alturas cualquier comentario sobre el dualismo clásico.

Pero hay un tercer sesgo de tintes antropocéntricos-quizás el que más puede pasar desapercibido- que dificulta el análisis, y que es, además, correlato del anterior: la pretendida comprensión del todo a partir de la parte, siendo la parte, en este caso, el ser humano socializado y moldeado por la cultura. Ateniéndonos a la analogía del agua: tratándose el agua de una realidad emergente y, por lo tanto, diferente, aunque dependiente del hidrógeno y el oxígeno, sería absurdo esperar que allá donde hay hidrógeno u oxígeno hay necesariamente agua; por consiguiente, ¿̇no carece de sentido buscar en la naturaleza fundamentos éticos humanos que debieran ser, entonces, identificables en otras especies? Dicho de otra manera: la experiencia humana subjetiva deviene en realidad simbólica estructurada por el lenguaje y su

\footnotetext{
${ }_{5}$ El materialismo racional o ilustrado, formulado en 1953 por Gaston Bachelard y promovido posteriormente por Jean Pierre Changeux, es un modelo teórico integrador que, desde una concepción evolucionista de la conciencia, describe el cerebro como un órgano estructurado a partir de disposiciones biológicas, pero también por condicionantes socioculturales, lo que lo hace, además, plástico, proyectivo y narrativo, siendo la emotividad «la marca característica de la conciencia desde el punto de vista de la evolución" (Evers, K. Neuroética. Cuando la materia se despierta, Katz, Madrid, 2010, p. 69).

${ }^{6}$ El posicionamiento de Searle respecto al reduccionismo mecanicista y el dualismo clásico es clave como punto de referencia para avanzar en la perspectiva del materialismo ilustrado. Su concepción de la conciencia como una emergencia de la actividad neuronal con categoría de propiedad, en este caso del cerebro, representa la asunción de que la experiencia de la conciencia, objetiva y subjetiva, tiene un soporte material, físico, y, por tanto, sujeto al proceso evolutivo y, en consecuencia, íntimamente ligado a la supervivencia.

7 Searle, J. El misterio de la conciencia, Paidós, Barcelona, 2000, p. 30.
} 
sintaxis ${ }^{8}$, además de las representaciones universales que son expresión de la vivencia emocional de los individuos -he ahí la clave de la singularidad humana y de la cultura-; ¿ cómo extrapolar, pues, un fenómeno experiencial simbólico, con su infinidad de variables, muchas de las cuales son igualmente simbólicas, a un ámbito en el que solo están presentes algunas de esas innumerables variables y no precisamente las simbólicas? Pareciera que contradigo en este punto mi argumento. Al contrario, solo aspiro a abrir, en la medida de lo posible, la perspectiva, superando esos tres sesgos, lo cual me sitúa en el centro de mi argumentación: el ser humano opera en dos, digamos, «dimensiones» de la realidad interrelacionadas e interdependientes; una es el entorno y la experiencia sensorial y emocional de la interacción con este, que es objetiva, directa, física y, por consiguiente, biológica -los sentidos, el sistema nervioso y el cerebro hacen que lo sea-; la otra es subjetiva, indirecta, y se construye simbólica y representacionalmente a partir de la experiencia objetiva y emocional previa y emplea como soporte el lenguaje; por tanto, si pretendemos emprender una búsqueda objetiva de la ética en la naturaleza no podemos hacerlo desde la subjetividad humana, sino desde su objetividad. Una ética natural e inmanente, en términos spinozistas, lo será, entonces, no porque su manifestación halle encuadre sintáctico en la subjetividad de la cultura, sino porque ha de ser observable en la naturaleza y, además, universal. ¿Es posible concebir una ética natural, ajena a la experiencia simbólica y subjetiva del ser humano, pero, por natural y, por tanto, inmanente, inherente a la condición humana? La hipótesis de un sí como respuesta requiere matices, pero es posible basándonos en el reconocimiento que el materialismo ilustrado hace de la naturaleza humana y de las sociedades humanas como resultado condicionado por la propia evolución del cerebro y de los entornos en los que este ha interactuado e interactúa, y en los que la especie, en este caso, ha prevalecido, razón suficiente para adoptar el reclamo de Kathinka Evers de asumir «un programa científico constructivo, interdisciplinario y cargado de responsabilidad $"$. En cualquier caso, hablaríamos de un materialismo flexible, por consiguiente, no reduccionista, que permitiría una filosofía de conjunto, seria y no parcelaria, en cuyo origen podríamos, con justicia, situar a Spinoza y su filosofía del conocimiento, que hace de lo objetivo y lo subjetivo, precisamente, dimensiones interdependientes de una misma realidad que se manifiesta en diversos escenarios materiales y que, en su vastedad, nos es epistemológicamente inabarcable y, como tal, solo cognoscible limitadamente por aproximación, es decir, como sujetos conscientes y, en consecuencia, aptos para la comprensión de la inmanencia.

8 Ibidem, p. 27: «La sintaxis no es intrínseca a la física del sistema, sino que está en el ojo del observador»; esta es una clara afirmación de Searle respecto a la subjetividad de lo simbólico como cualidad de la conciencia y realidad igualmente emergente de esta, solo susceptible de ser analizada y valorada en el ámbito humano. Del mismo modo que la conciencia no es el cerebro, pero emerge de las funciones de este, el lenguaje simbólico no es la conciencia, pero emerge de esta. Dicho de otro modo, que haya cerebro no significa que necesariamente tenga que haber lenguaje simbólico.

9 Evers, K. Neuroética. Cuando la materia se despierta, Katz, Madrid, 2010, p. 188. 


\section{NOMBRE PARA UN FUNDAMENTO ÉTICO NATURAL}

¿Dónde identificar esta ética natural? Quizás, para poder dar una respuesta y en aras de salvaguardar la objetividad, habría que traspasar las fronteras del propio concepto ética, incluso dejarlo a un lado, y considerar este como el constructo verbal cuya significación hace referencia al carácter subjetivo, propiamente humano, de una cualidad natural hipotéticamente presente en todas las formas de vida. Sería un modo de salvar el sesgo antropocéntrico al que antes aludía. Evitaríamos, así, la confusión entre el concepto en tanto que categoría y el concepto en tanto que materia o disciplina de estudio. Como alternativa, propongo referirnos a precursores éti$\cos$, es decir, principios naturales que, siendo universales y, por consiguiente, comunes a todas las especies, podrían considerarse además como fundamentos naturales de la ética humana, que sería, en consecuencia, una realidad subjetiva, claramente simbólica e incluso cuestionable, pero con principios sólidos, objetivos y evidentes. Para explicarlo mejor, planteo una analogía tomando como referencia la alimentación: el sentido del alimento es su función nutritiva; todas las especies se alimentan, los humanos nos alimentamos, pero la cultura ha hecho que la nutrición se convierta casi en una función subsidiaria de la experiencia del comer, y por ello los humanos somos una especie que, aunque se alimenta, no siempre se nutre, porque la experiencia del comer, cargada de componentes psicológicos, emocionales y simbólicos, pocas veces tiene como objetivo la nutrición. Del mismo modo, la ética humana, aun conteniendo un sustrato natural, no siempre responde, al menos en apariencia, a este de manera directa. Por ello, para aspirar a dar con esos precursores éticos naturales, comunes a todas las especies, necesariamente hemos de observar la vida y su desarrollo evolutivo a lo largo de casi cuatro mil millones de años, es decir, más allá de lo humano para poder comprender, verdaderamente, lo humano, por redundante que parezca.

El darwinismo es claro en su afirmación de que no hay historia humana ajena a la historia natural, por esta razón, todo estudio serio respecto a la naturaleza humana y sus singularidades debe mirar a las demás especies en busca de vínculos y no de diferencias. Me permito recurrir a Alasdair MacIntyre ${ }^{10}$ en este sentido, para quien la comprensión de lo humano requiere del estudio de las características y comportamientos de los animales no humanos. Así, sostiene que existen ciertas capacidades y facultades que propician el lenguaje singular humano como una extensión o derivación, considerando a estas como prelingüísticas y, como tales, presentes en otras especies. Para MacIntyre, estas facultades dependerían de mecanismos y recursos biológicos previos y han de ser abordadas en términos de continuidad, es decir, el lenguaje humano vendría a ser el peldaño evolutivo más com-

10 Macintrre, A., Animales racionales y dependientes. Por qué los seres humanos necesitamos las virtudes, Paidós, Barcelona, 2001. 
plejo que contiene todas las características biológicas del proceso que lo propicia ${ }^{11}$. De hecho, numerosos autores sostienen que, en su origen ${ }^{12}$, el Homo sapiens no era como lo es ahora, porque carecía de lenguaje hablado, es decir, de una sintaxis, «aunque su cerebro fuera ya esférico y tuviera la capacidad simbólica en potencia y su aparato fonador estuviera listo para articular sonidos» ${ }^{13}$. Volvemos a las facultades prelingüísticas de MacIntyre, en plena resonancia con la potencia spinozista, ese llegar a ser, que parece evidenciarse en determinados hallazgos de autores como el paleoantropólogo Ian Tattersall ${ }^{14}$. La potencia vendría a ser, no ya una clave adaptativa, sino exaptativa, término este, exaptación - preadaptación-, acuñado por Tattersal para referirse, precisamente, a «innovaciones espontáneas que carecen de función o que juegan un papel muy diferente al que finalmente tienen", conteniendo en potencia la capacidad posterior. La consonancia con las facultades prelingüísticas que defiende MacIntyre es evidente. Sin embargo, esa morfología cerebral y esa capacidad funcional requirió de procesos complementarios para eclosionar en el lenguaje simbólico, algo que sucedió hace muy poco si consideramos la franja de tiempo que ocupa el Sapiens en la historia de la vida, y cuestión sobre la que apenas hay certezas, pero sí muchas hipótesis, fundamentalmente en cuanto a si se trata de una adquisición motivada por el entorno, si estaba o no presente también en los neandertales, o si representa lo que algunos han convenido en llamar salto cuántico. En cualquier caso, nos sirve para considerar, al menos por aproximación, la existencia de precursores éticos del mismo modo que, como todo apunta, los tuvo -y tieneel lenguaje simbólico y, a su vez, el habla. Pero surge un problema epistemológico al respecto: el objeto de estudio. Evers sitúa en Francis Bacon el origen de la confluencia entre la ética, como materia filosófica, y la ciencia; hablamos, por tanto, de un largo recorrido histórico nacido de la necesidad de respuesta respecto a qué y cómo es, objetivamente, el ser humano, y que hoy cristaliza en una disciplina que levanta tanto interés como desaire: la neuroética, un concepto de vanguardia para la investigación de vanguardia que requiere de una clara apertura epistemológica si se pretende útil, y que ha permitido que filosofía y neurociencia se den la mano. Pero sucede que, habiéndose convertido el cerebro humano en la caja de todos los misterios, manteniéndose así el sesgo mecanicista y, por tanto, reduccionista, al que me refería anteriormente, debido, principalmente a los esfuerzos por identificar adecuadamente el origen de la conciencia, toda investigación ya realizada o en ciernes toma

${ }^{11}$ Ibidem, p. 75: «Reconocer que existen estas precondiciones animales para la racionalidad humana obliga a pensar acerca de la relación entre el ser humano y los miembros de otras especies inteligentes en términos de escala o espectro, y no de una sola línea divisoria entre ellos y nosotros».

${ }^{12}$ Hace unos 200000 años.

13 Arzuaga, J.L., op. cit, (pos. 5995).

${ }_{14}$ Considera Tattersall que los mecanismos del habla surgieron por mutación mucho tiempo antes de que quedaran configurados para poder articular sonidos, $c f$. Ian TatTersall, The monkey in the mirror. Essays on the science of what makes us human, Harcourt, San Diego, California, 2005, p. 51 y ss. Citado en R. Bartra, Antropología del cerebro. Conciencia, cultura y libre albedrio, Pre-textos, Valencia, 2014, p. 35 y ss. 
por objeto principal de estudio el cerebro, quizás por ese otro sesgo antropocéntrico que tiende a tomar el humano como la medida referencia de todo cerebro ${ }^{15}$. ¿Podríamos, sin embargo, dejar a un lado, de momento, las estructuras y funciones cerebrales, con su inmensa trama neuronal, y buscar precursores éticos de otra manera, que no en otra parte? Me aventuro a afirmar que sí, y ya que no es este el momento ni el lugar para entrar en debates adyacentes al respecto, considero que es posible afirmar también que no hay cualidad o característica humana susceptible de ser desligada del proceso evolutivo, luego ¿es lo humano, es decir, la singularidad humana, con todo lo que ello implica, una emergencia derivada de una sucesión de emergencias precedentes? A partir de este punto, es precisa, entonces, una importante consideración: ningún fenómeno evolutivo, sea la emergencia de la conciencia o la eclosión del lenguaje simbólico, extingue aquello que lo ha hecho posible; muy al contrario, mantiene una relación directa y condicionante. El neurocientífico Antonio Damasio sostiene, en este sentido, que «nuestra mente y nuestras culturas están conectadas con los procedimientos y los medios de la antigua vida celular, así como de muchos seres vivos intermedios ${ }^{16}$. Sirve como recurso, nuevamente, la analogía del agua de John Searle. Por otro lado, puesto que cada especie posee su especificidad y todas han de ser valoradas en sus características y cualidades, como en el caso humano, en tanto que emergencias de emergencias precedentes, todas han de compartir características en tanto que manifestaciones de un mismo fenómeno, es decir, características y cualidades que no son específicas de una u otra especie, sino que lo son del fenómeno de la vida -Naturaleza Naturante en Spinoza-, y por eso están presentes en todos los modos en que esta se manifiesta-Naturaleza Naturada-. Solo remitiéndonos a los mecanismos básicos de la vida cabe la hipótesis de la existencia de precursores éticos, que no solo funcionarían como base teórica para hablar de una ética natural, sino que justificarían la inmanencia spinozista superando todo reduccionismo: lo humano es y, por lo tanto, ha de observarse, estudiarse y comprenderse en la naturaleza, que es donde único es; por ello, no hay una naturaleza humana, sino una expresión de la naturaleza que llamamos humana por su singularidad, es decir, que no es contraria, ni diferente, ni superior a cualquier otra expresión de esa misma naturaleza, sino singular ${ }^{17}$, puesto que «la naturaleza es siempre la misma, en todas partes [...]; son siempre las mismas, en todas partes, las leyes y reglas naturales según las cuales ocurren las cosas y pasan de unas formas a otras» ${ }^{18}$.

15 ¿Progresionismo soslayado?, me pregunto.

16 Damasio, A., El extraño orden de las cosas. La vida, los sentimientos y la creación de las culturas, Destino, Barcelona, 2018, p. 48.

${ }_{17}$ Spinoza: «Es imposible que el hombre deje de ser una parte de la naturaleza y que no siga el orden común de ella». Cf. SpinOzA, Ética, iv, apéndice, capítulo 7.

18 Spinoza, Ética, iII, Prefacio. 


\section{¿UN PRECURSOR ÉTICO UNIVERSAL?}

Necesariamente lo humano ha de remitirnos a los mecanismos básicos de la vida, luego la dimensión ética humana también. ¿Qué hay, pues, en la vida, que pudiera ser considerado precursor ético y que haya derivado, por causa de las sucesivas emergencias a lo largo del proceso evolutivo, en la ética tal y como la concebimos teórica y normativamente, e incluso, y sobre todo, experiencialmente? Como sostiene Arsuaga, «la evolución es una sola y tiene patrones generales que se aplican a todos los grupos biológicos $\aleph^{19}$; es en esos patrones generales donde podemos ir en busca de nuestros precursores éticos, entendiendo que se trata de los cimientos biológicos sobre los cuales el pensamiento simbólico humano, a través de la cultura, ha construido la dualidad bien-mal a partir de la cual se fundamenta la ética como ámbito teórico desde el que adquieren utilidad y sentido los llamados valores, pero del mismo modo que un tejado no es el cimiento de la casa que cubre, pero depende de este para que su razón de ser tejado - la casa- se mantenga, no necesariamente los valores derivados de la ética tienen una correspondencia directa con los precursores éticos que los cimientan -esos patrones generales que se dan en todas las formas de vida-, pero ello no invalida la hipótesis de que tales patrones puedan ser considerados precursores éticos.

Yendo en pos de un punto de anclaje teórico y discursivo que me permita avanzar en la argumentación, se me ocurre el siguiente: la vida, para ser, necesita durar, mantenerse; si la vida no dura, se extingue, desaparece. ¿Cómo dura la vida? $\mathrm{O}$, lo que es lo mismo, ¿̨cómo duran las formas de la vida, los modos que define Spinoza, las máquinas de supervivencia, en palabras de Richard Dawkins en su propuesta sobre el gen egoísta ${ }^{20}$ ? La respuesta a esta pregunta, o un acercamiento a ella, la sitúa Arsuaga en el metabolismo, que se basa, a su vez, en un desequilibrio termodinámico que explica citando a Erwin Schrödinger y su libro Qué es la vida (1944), en el que el físico sostiene que la célula tiene que hacer la difícil tarea de enfrentarse al segundo principio de la termodinámica, según el cual «todo sistema completamente cerrado tiende inevitablemente al aumento de la entropía, es decir, se desliza hacia el estado de máximo desorden (o de mínima organización), que es el de equilibrio termodinámico o [...] de muerte. [...] Para mantener constante el orden y la organización dentro del organismo, tiene que incrementarse la entropía (el desorden y la desorganización) fuera ${ }^{21}$. Por ello, para Arsuaga, la clave del metabolismo es que todo organismo busca deshacerse de la entropía que genera mientras vive $y$, en consecuencia, «la vida está en permanente desequilibrio termodinámico ${ }^{22}$, pero un desequilibrio estable. El origen de este proceso se remonta en el tiempo hasta el llamado caldo primigenio, donde surge la célula «como un extraordinario conjunto

\footnotetext{
19 Arsuaga, J.L., op. cit. (pos. 106).

20 Daw kins, R., El gen egoista extendido, Salvat, 2017, p. 28.

21 Arsuaga, J.L., op. cit. (pos. 1258).

22 Ibidem (pos. 1272).
} 
de moléculas químicas con afinidades concretas y con las consiguientes reacciones químicas autoperturbadoras de ciclos repetitivos de pulsaciones, latidos y compases $»^{23}$. Para poder durar-resumiéndolo mucho-, la célula debía extraer del entorno la energía suficiente, y debía hacerlo con una eficacia que garantizara la estabilidad, de manera que esa misma energía era empleada para su autorreparación y para eliminar los desechos resultantes del proceso. Pero hubo algo más, un fenómeno en el que el neurocientífico Antonio Damasio pone especial énfasis: la estabilidad a la que tendió la célula proporcionaba un excedente de energía que le permitía «optimizar la vida y proyectarla hacia el futuro ${ }^{24}$. Y de este modo, señala Damasio, la célula prosperó y, en consecuencia, propició la reproducción. Se trata, por tanto, más que de un proceso, de una combinación de procesos, o un proceso de procesos, incluso podríamos decir metaproceso, que recibe el nombre de homeostasis, y por el que «se contrarresta la tendencia de la materia hacia el desorden con el fin de mantener el orden, pero a un nuevo nivel, el que permite un mayor grado de estabilidad vital $\aleph^{25}$. El impulso natural de la célula de durar en el tiempo no puede más que considerarse como capacidad para mantenerse viva, es decir, perpetuarse y proyectarse en el tiempo. Damasio utiliza, incluso, la expresión intención irrefrenable ${ }^{26}$-con todas las salvedades respecto al término «intención», dado que Damasio no pretende telos alguno sino concretar lingüísticamente el proceso para garantizar su comprensiónpara referirse a ese impulso natural y lo conecta con acierto con el conatus expresado por Spinoza en las proposiciones 6, 7 y 8 de la Parte Tercera de su Ética ${ }^{27}$. Esta concepción de la homeostasis nos acerca a la posibilidad de identificar cualidades propias de la vida que pudieran ser consideradas precursores éticos. Para Damasio, la homeostasis abarca mucho más que la mera regulación equilibrada de los procesos biológicos; se trata de una propiedad de la vida que ha impulsado la selección natural y favorecido la evolución de todas las especies. El planteamiento de Damasio de esa propiedad fundamental del fenómeno de la vida como intención, en correspondencia con el conatus, lo empuja hacia un giro aún más spinozista, reformulando la homeostasis como "poderoso imperativo, carente de reflexión o expresión, que permite a cualquier organismo vivo, pequeño o grande, resistir $\nu^{28}$ y permanecer, durar en el tiempo. Si para muchos autores la revolución cognitiva que propone Yuval N. Harari, y que hizo posible la expansión de las estructuras cerebrales y un aumento del cerebro consiguiente de las mismas, es la causa de la cultura y del lenguaje sim-

${ }^{23}$ Damasio, A., El extraño orden de las cosas. La vida, los sentimientos y la creación de las culturas, Destino, Barcelona, 2018, p. 58.

${ }^{24}$ Ibidem.

${ }^{25}$ P. 59.

${ }^{26}$ P. 60.

27 Spinoza: «Cada cosa se esfuerza, cuanto está a su alcance, por perseverar en su ser»; Proposición 7: «El esfuerzo con que cada cosa intenta perseverar en su ser no es nada distinto de la esencia actual de la cosa misma»; y Proposición 8: «El esfuerzo con que cada cosa intenta perseverar en su ser no implica tiempo alguno finito, sino indefinido", $c f$. SpINozA, Ética, III, 6.

${ }_{28}^{28}$ Damasio, A., op. cit., p. 44. 
bólico, con todo su entramado de convenciones, reglas y, por extensión, de la moralidad y los principios éticos que nos hemos dado como reguladores de la conducta, para Damasio la verdadera causa, el origen cierto de nuestra humanidad no es un fenómeno fortuito provocado por causas ambientales que forzaron la activación de mecanismos adaptativos, sino, precisamente, el poderoso imperativo, el conatus, el impulso homeostático. Se refiere, por ello, a una homeostasis sociocultual ${ }^{29}$ que opera de la misma forma que la homeostasis orgánica por ser una proyección de esta. Para Damasio los avances culturales responden «a una detección del desequilibrio en el proceso de la vida y tratan de corregirlo dentro de las limitaciones que impone la biología humana y las restricciones que dicta el entorno social y físico» ${ }^{30}$. De este modo, todo concepto normativo, toda regla social, todo sistema moral e incluso todo sistema de justicia, son formas de respuesta ante los desequilibrios que se dan en la sociedad y ponen en peligro al colectivo y a los individuos. Pero no se trata de una traslación casual ni de una coincidencia, sino de un proceso complementario y dependiente de la homeostasis orgánica, cuya acción ocurre en el nivel superior de la mente, en la corteza cerebral. Entre esta homeostasis básica y la homeostasis sociocultural intervienen las emociones como reacciones al desequilibrio, y esto prueba, a juicio de Damasio, lo que define como regulación híbrida de la vida a cargo del cerebro humano ${ }^{31}$. Dicho de otro modo, «la homeostasis sociocultural se ańadió como una nueva capa funcional de gestión de la vida, pero la homeostasis biológica siguió allí»" ${ }^{32}$. Hay una clara interacción entre ambas formas de homeostasis y la amplitud de las implicaciones de esta interacción en el comportamiento humano es aún un misterio, pero representa una valiosa vía de estudio que nos puede permitir la identificación de nuestros precursores éticos. En este sentido, Damasio traspasa la frontera de la emergencia de la conciencia como punto de partida de una moralidad que surge como consecuencia de la autoconciencia, que, a su vez, condujo al desarrollo de un pensamiento autobiográfico que empujó a la reflexión, la observación, la deliberación y la búsqueda y concreción de conocimiento. Surgen, a partir de ese momento evolutivo, los mitos, los símbolos y la dinámica mental que hace del Sapiens un constructor de representaciones incansable, que se reconoce como agente activo en el proceso de la vida y que siente el impulso de protagonizar su propia experiencia vital. Ahí está el origen de la ética de hoy, asentado «sobre comportamientos premorales [...] que la naturaleza había venido mostrando desde mucho antes de la aparición de una conciencia reflexiva $»^{33}$. Esta alusión de Damasio a comportamientos premorales nos pone, sin duda, en la pista de nuestros precursores éticos, ya que implican lo que el neurocientífico define como sabiduría neurobiológica

29 Damasio, A., Y el cerebro creó al hombre. ¿Cómo pudo el cerebro generar emociones, sentimientos, ideas y el yo?, Destino, Barcelona, 2010, p. 437.

30 Ibidem.

31 Ibidem.

32 Ibidem, p. 438.

33 Ibidem, p. 436. La conciencia reflexiva proporciona los recursos para que el individuo humano observe su conducta y comience a interpretarla y modelarla en aras de mejorar su existencia. 
congénita ${ }^{34}$ y reconoce como cualidad del conatus spinozista, considerando al filósofo verdadero auspiciador de la neurociencia contemporánea.

Si la homeostasis, como señala Damasio, se halla en el corazón mismo de la vida, ¿qué podría ser considerado en ella como precursor ético? Indudablemente, no hay escenario más apropiado, por global, para la búsqueda de precursores éticos, y, dado que todas las formas de vida están sujetas a la dinámica de la homeostasis, en todas han de darse características que podrían ser consideradas puntos de partida de la especificidad evolutiva posterior; es decir, la singularidad, necesariamente, debiera contener mecamismos protosingulares que, del mismo modo que sucedió con el desarrollo de la complejidad del cerebro, de la conciencia por causa de esta, del lenguaje y, finalmente, del lenguaje simbólico, son comunes a todas las especies por ser cualidades del fenómeno de la vida. Pero si todas estas emergencias son movidas por el mismo principio, todas suponen un inmenso conjunto de estrategias adaptativas que operan como acción consecuente de la homeostasis; es decir, el poderoso imperativo, el conatus, impele al cerebro a la elaboración de mecanismos adaptativos que permiten al ser humano, como individuo y como especie, y a toda forma de vida, durar en el tiempo. Estos mecanismos adaptativos se basan en la experiencia resultante de la interacción con el medio y de la información contenida en los genes que porta el individuo, y su objetivo es uno, claro y específico: la supervivencia. Para los naturalistas como Arsuaga la supervivencia es previa al impulso de reproducción, es decir, «son aquellos individuos que tienen éxito en la vida, porque están bien adaptados, los que producen más descendientes ${ }^{35}$; para los considerados ultradarwinistas, como Dawkins o Maynard Smith, «los individuos se afanan para transmitir el mayor número posible de sus propios genes. [...] Unos miran a los genes y otros a los individuos y su relación con el medio, es decir, su ecología y sus adaptaciones ${ }^{36}$. En cualquier caso, y al margen de este debate, la cuestión central sigue siendo ese durar en el tiempo, la supervivencia, que es una consecuencia de la homeostasis, y que hace que "cada cual se esfuerce cuanto está en su mano por conservar su ser $\aleph^{37}$, decía Spinoza. Dicho de otro modo, la supervivencia es el valor en liza en la adaptación, fenómeno común a todas las formas de vida; luego, por la supervivencia, la vida permanece, tiene continuidad en sus modos, pero no solo eso: la vida, además, prevalece.

La clave de la definición de Damasio de la homeostasis como poderoso imperativo reside en el hecho de que hace posible que cualquier organismo vivo, independientemente de su tamaño y sus características, pueda resistir la tensión propia de esa experiencia balanceada entre el orden y el desorden ínsita del proceso metabólico y, además, prevalecer. Se trata de dos aspectos resultantes de la propia actividad homeostática orientados al mismo fin, o, mejor dicho, a la misma función: permane-

34 Damasio, A., En busca de Spinoza. Neurobiología de la emoción y los sentimientos, Destino, Barcelona, 2010, p. 94.

35 Arsuaga, J.L., op. cit. (pos. 4652).

36 Ibidem.

37 Spinoza, Ética, Iv, 18, Escolio. 
cer, durar en el tiempo. Pero ¿no basta con sobrevivir? En este punto Damasio realiza una extraordinaria aportación identificando estas dos funciones de la homeostasis o poderoso imperativo: por un lado, la resistencia "produce la supervivencia y se da por hecho sin ninguna referencia ni reverencia específicas cuando se considera la evolución de cualquier organismo o especie»" ${ }^{38}$; por otro lado, la prevalencia «asegura que la vida se regule dentro de manera que no solo sea compatible con la supervivencia, sino que contribuya también a la prosperidad, a una proyección de la vida hacia el futuro de un organismo o especie» ${ }^{39}$. Esta distinción es fundamental y nos permite considerar la prevalencia como precursor ético primordial en tanto que no solo participa del «objetivo» biológico de la supervivencia, sino que lo dota de sentido puesto que lo garantiza, aboca a la prosperidad, que es lo único que hace posible la durabilidad; por ello, la condición humana, al igual que toda forma de vida, se halla dotada de una motivación muy concreta: «Resistir y proyectarse hacia el futuro en cualquier circunstancia» ${ }^{40}$. Esta misma afirmación de Damasio la encontramos en Spinoza, para quien la naturaleza no solo es causa de que las cosas empiecen a existir sino de que perseveren en su existencia ${ }^{41}$. Pero quizás debiera ser matizada la expresión «objetivo biológico de la supervivencia»; no debe ser entendida como finalidad propiamente dicha, sino, en todo caso, como una forma de nombrar el efecto homeostático que deriva en función. No existe el objetivo de prevalecer puesto que la prevalencia es simultánea al resto de los procesos homeostáticos, luego no hay telos, ya que no hay realidad alguna alcanzable porque ya es, por eso es preciso atender al significado de la expresión como efecto en el sentido de función derivada, como indicaba antes. Por otro lado, bien vale una reflexión amplia acerca de un hecho ligado a la prevalencia que desbarata toda dualidad en la concepción del fenómeno de la vida -es de gran arraigo cultural la idea de la muerte como final de la vida y en consecuencia antagónica respecto a esta-: la vida empezó a ser y continúa siendo, sin contener en ella predisposición alguna a su propia finalización. En otras palabras: la vida es un fenómeno expansivo y, como tal, se promueve a sí misma, solo puede ser, por ello, probiótica ${ }^{42}$. La muerte no es su contrario en modo alguno, porque la muerte de los organismos complejos no aniquila el fenómeno y, además, forma parte del propio proceso evolutivo, o si se prefiere, de la propia regulación homeostática en aras de la prevalencia, por paradójico que parezca, luego la vida no es ni puede ser protanática ${ }^{43}$.

${ }^{38}$ Damasio, A., El extraño orden de las cosas. La vida, los sentimientos y la creación de las culturas, p. 44 .

39 Ibidem.

${ }^{40}$ Ibidem, p. 53.

${ }^{41}$ SpInoza: «Se sigue de aquí que Dios no solo es causa de que las cosas comiencen a existir, sino también de que perseveren en la existencia». Sobra decir a estas alturas que toda referencia a Dios en Spinoza ha de ser considerada como sustancia pura o naturaleza, no como deidad propiamente dicha. Cf. Spinoza, i, 24, Corolario.

${ }^{42}$ Que promueve y favorece la vida.

${ }^{43}$ Que promueve y favorece la muerte. 
A modo de conclusión podemos afirmar que la prevalencia es la garantía homeostática de la vida y, por tanto, precursor ético primordial porque propicia estados vitales que favorecen la existencia de los individuos, de las especies, de la propia vida. Si pretendemos hallar un precursor ético tomando como objeto de análisis al individuo y, particularmente, su cerebro, erramos; si tomamos como objeto de análisis a las especies mediante la búsqueda de comportamientos o cualidades que pudieran ser considerados comunes, erramos. No es el individuo ni la especie, sino la vida -Naturaleza Naturante- la que prevalece a través de los individuos y de las especies, que son sus modos -Naturaleza Naturada-, manifestaciones singulares de una misma realidad, y lo hace por medio de la homeostasis, presente, como indica Damasio, «a escala microscópica, en cada célula viva, y podemos imaginarla a escala macroscópica, en toda la naturaleza: en nuestros organismos, constituidos por billones de células, en los miles de millones de neuronas de nuestro cerebro, en la mente que emerge de nuestros cerebros encarnados en un yo, y en los innumerables fenómenos culturales que los diferentes colectivos humanos han construido y modificado durante milenios» ${ }^{44}$. Por otro lado, Dawkins, como otros ultradarwinistas, pone el acento en los genes, identificando estos como la unidad de selección natural por excelencia ${ }^{45}$. La teoría genética ultradarwinista aporta una perspectiva, a mi juicio, disociada. Identificar el gen como el mecanismo básico de la supervivencia obvia el principio prevalente de la vida, puesto que, si se considera a los organismos como meras máquinas de supervivencia -es así como los define Dawkinspara los genes, siendo estos los portadores del valor de supervivencia, se pierde de vista la homeostasis como fenómeno fundamental del fenómeno global que es la vida. La afirmación de un "egoísmo» del gen, en el sentido de que es este el que busca durar en el tiempo a través de los organismos, tiene, así, demasiados peros. Dawkins se refiere a una lucha por la existencia que se remonta en el tiempo hasta los primeros replicadores, moléculas con la extraordinaria capacidad de hacer copias de sí mismas, a partir de los cuales surgió una nueva forma de estabilidad determinante en la selección natural. Las copias podían tener errores y todas se nutrían del caldo primario en un proceso, precisamente, expansivo que iba en detrimento de la estabilidad al agotarse los recursos de este, lo cual dio lugar a otra condición para la supervivencia: la competencia. De ese modo, «cualquier copia con errores que diese como resultado un nivel más alto de estabilidad o una nueva forma de reducir la estabilidad de los rivales, era, automáticamente, preservada y se multiplicaba» ${ }^{46}$. Ese es el punto clave de la teoría del egoísmo genético según la cual un gen se abre paso evolutivamente hablando en detrimento de otros para preservarse, y para ello se vale de otros genes y del organismo que, del mismo modo, utiliza para ese fin. Sin embargo, aun pudiendo considerarse este argumento, no puede obviarse que lo

44 Damasio, A., El extraño orden de las cosas. La vida, los sentimientos y la creación de las culturas, p. 60.

${ }_{45}$ Daw kins, R., "No es la especie, ni el grupo, ni siquiera, estrictamente hablando, el individuo. Es el gen, la unidad de la herencia». El gen egoista extendido, op. cit., p. 15.

46 Ibidem, p. 26. 
propicia la homeostasis, luego la competencia y la estabilidad son condiciones subsidiarias de la prevalencia; los genes han de ser considerados, entonces, no ya unidades últimas, y mucho menos precursores éticos, sino soporte a través del cual acontece la prevalencia como cualidad. Si no son los individuos ni las especies, tampoco son los genes; es la vida. La atención ha de ubicarse en el fenómeno de la vida que, por más que haya sido observado, analizado y reflexionado, sigue siendo un verdadero misterio, sobre todo en sus orígenes.

La consideración, pues, de la prevalencia como precursor ético primordial abre la puerta a la búsqueda de otras cualidades de la vida que pudieran operar igualmente como precursores, pero el principal, sin duda, ha de ser la prevalencia, porque podemos afirmar que todos los procesos químicos que participan de la homeostasis y cristalizan en prevalencia, todos sin excepción, tienen que ver con los ajustes adaptativos de los organismos necesarios para garantizar la integridad y la salud, que es, precisamente, lo que permite prevalecer, no solo sobrevivir. La integridad y la salud solo pueden ser tenidas como condiciones constituyentes de un estado que, además, cultural e incluso evolutivamente, ha sido el objeto de toda acción de toda forma de vida: el bienestar, que es la consecuencia de la integridad y la salud. Podemos concebir el bienestar, en definitiva, como el estado prevalente por excelencia, porque aquella estabilidad motivadora de los primeros replicadores y actuales genes -la competencia habría de ser observada como capacidad efectiva y no sentido o razón- solo era y es posible desde la salvaguarda de la integridad y la conservación de la salud, por ello hemos de aceptar la prevalencia como precursor ético primordial, porque de ese bienestar ha dependido y depende hoy la percepción y concepción que los individuos tienen de la realidad, de sí mismos y de los demás, lo cual impregna toda la experiencia existencial, en la que participan emociones, sensaciones, sentimientos, pensamientos y, por supuesto, valores y principios éticos. Se trata, por acabar con Spinoza, de que «el esfuerzo por conservarse es el primero y único fundamento de la virtud. Pues no puede ser concebido ningún otro principio anterior a él, y, sin él, no puede concebirse ninguna virtud ${ }^{47}$.

Recibido: 1 de junio de 2020; ACeptado: 26 de junio de 2020

47 Spinoza, Ética, iv, 22, Corolario. 
